also says that several companies, particularly when referring to the less tangible effects of spin-off pointed out that the benefits are likely to disappear if the project does not go into full production. Companies involved in the Advanced Passenger Train development, which the centre also consulted in the course of the survey, expressed similar views.

The report attacks the assumption that spin-off could be used in part as justification for projects that otherwise are uneconomical, and points out that "for the majority of companies supplying the Concorde programmes the work was of a straightforward type not involving commercial or technical conditions any more strenuous than those normally met".

The dependence of supply firms on Concorde varied considerably, contracts ranging from $£ 3.7$ million to $£ 320$, and the report also found that the economic dependence of companies on Concorde work was surprisingly low-only one quarter of firms had order-values of more than one-sixth of their annual turnover, and only six firms of more than half. A further quarter had ordervalues of only one per cent of their annual turnover.

The survey was only concerned with assessing how many companies benefited from spin-off as a result of work on Concorde, and in the types of spinoff experienced-no attempt being made to assess the economic value of the spinoff. The centre refused to hazard a guess at the percentage value of the spin-off from the $£ 500$ million spent on Concorde to date, and without any guide to this the figures in the report are less meaningful. Its conclusions are in the main only those expected, some of them so obvious as to be barely worth making-for instance that sub-contractors who supply specifically designed non-standard items benefit more from spin-off than suppliers who provide standard items. The centre says that more studies are needed to assess the economic value of spin-off, at the same time suggesting that it may never be quantifiable-because so much of it is intangible - in terms that can be taken into account in the cost/benefit analysis of large programmes. The centre hopes, however, that its report will provide a yardstick against which some sort of assessment of the economic value of spin-off can be made.

\section{EDUCATION}

\section{No A-level Electronics}

THE study of electronic systems in school sixth forms is apparently regarded by the Schools Council on the Curriculum and Examinations as excessively vocational and specialized. As a conseanence. the council has not al- lowed the Associated Examining Board to set an experimental A-level examination based on a syllabus devised by Professor G. B. B. Chaplin and his colleagues of the Department of Electrical Engineering Science at the University of Essex.

Work on the syllabus started in 1966 and the project came to fruition when members of the Electrical Engineering Science Department began to teach a sixth-form course at Colchester Royal Grammar School in 1970. The Associated Examining Board considered that the syllabus would provide a reasonable basis for an A-level examination and duly sought permission from the Schools Council to set an examination for the eight boys in the first year sixth form who have been taking the course as an extra subject. The Schools Council handed down its decision on the grounds that the course did not satisfy the criteria by which the suitability of A-level courses is judged; one of these is that courses "should not be largely or wholly of a narrowly vocational character".

Professor Chaplin emphasized last week, however, that the electronic systems course is by no means a preuniversity training for electronic engineers but that it is a non-specialist course which would be equally useful to those not going to university. $\mathrm{He}$ also pointed out that the syllabus had been enthusiastically received by teachers attending vacation courses within his department.

The syllabus is divided into three parts-communication systems, control systems and computer systems-each of which is prefaced by some consideration of the relevant human functions, such as hearing, seeing, feedback and problem solving. Although the course concentrates on the underlying principles of electronic systems, the characteristics of electronic devices themselves can be examined in more detail as appropriate. Experimental work is an integral part of the course and includes, for example, measurement of the frequency response of the human ear and simple experiments with servomechanisms.

Professor Chaplin is not unduly discouraged by the attitude of the Schools Council and it is planned that the second half of the syllabus will be taught to another group of boys in the first year sixth form during the coming academic year. Meanwhile it seems likely either that another approach will be made to the council in the near future or that efforts will first be made to interest more and more teachers in the idea of a course on electronic systems-possily through the Association for Science Education and the National Electronics Council.

\section{Appointment}

Mrs Margaret Thatcher, Secretary of State for Education and Technology, announced this week the appointment of Professor R. C. O. Matthews as chairman of the Social Science Research Council in succession to $\mathrm{Mr}$ Andrew Shonfield. Professor Matthews, Drummond Professor of Political Economy at Oxford, will take over from Mr Shonfield on January 1, 1972. $\mathrm{He}$ is at present a member of the SSRC and is chairman of the council's Economics Committee as well as being a member of the Central Advisory Council for Science and Technology, the Council of the Royal Economic Society and the Executive Committee of the National Institute of Economic and Social Research.

\title{
Miscellaneous Intelligence
}

SWEDEN is reported to be the first West European country to introduce Chinese as an optional subject at the secondary school level. Twenty pupils at a Stockholm school are now studying Chinese as their third foreign language, after English and German or French. Most pupils at the equivalent level of education in Sweden study Spanish as their third language, and roughly 1,300 take Russian.

THE University of Leicester experiment to determine the precise position of the source $\mathrm{GX} 3+1$ was successfully flown from Woomera in Australia on September 26. It is hoped that the data obtained on this flight will lead to an improvement in the position known for this X-ray source from 2 arc min to better than 0.25 arc $s$ in the coordinate measured. This is achieved by determining the exact time at which the source disappears when it is eclipsed by the Moon. The flight took place aboard a Skylark sounding rocket, which was stabilized and "locked on" to the strong X-ray source Sco X-1 during the four minutes of observing time. The experiment and the Scorpius sensor were provided by the group working under Dr K. Pounds at Leicester. The determination of a precise position for GX3 1 may lead to its identification with an optical object; first results indicate that the flight was a complete success. 